\title{
Biophysical Basis of Resistance against Shoot Bug (Peregrinus maidis) in Different Genotypes of Rabi Sorghum
}

\author{
Indhusri Chavan $^{1 *}$, J.S. Awakanavar ${ }^{2}$ and A.P. Biradar ${ }^{3}$ \\ ${ }^{1}$ Department of Agricultural Entomology, UAHS, Shivamogga, Karnataka, India \\ ${ }^{2}$ Department of Agricultural Entomology, College of Agriculture, Bijapur, Karnataka, India \\ ${ }^{3}$ University of Agricultural Sciences, Dharwad - 580 005, Karnataka, India \\ *Corresponding author
}

\section{A B S T R A C T}

\begin{tabular}{|l|}
\hline Ke y w or d s \\
Shoot bug, \\
$\begin{array}{l}\text { Peregrinus maidis, } \\
\text { Sorghum genotype. }\end{array}$ \\
\hline Article Info \\
\hline $\begin{array}{l}\text { Accepted: } \\
\text { 07 September } 2017 \\
\text { Available Online: } \\
\text { 10 October } 2017\end{array}$ \\
\hline
\end{tabular}

A field experiment was conducted during 2013-14 at Agricultural collage Farm, Bijapur to investigate the effect of different dates of sowing on shoot bug population in Rabi sorghum. A total of seven genotypes were sown in a plot size of $2.4 \times 4.7 \mathrm{~m}$ with three replication in a randomized block design, the results revealed that among the seven genotypes Phule vasudha and BJV 44 were found to be superior by recording lowest shoot bug population per plant 9.10 and 9.80 number per plant respectively. While Phule yashodha, M 35-1, DSV 4, DSV 5 and Muguthi recorded maximum number of shoot bugs per plant.

\section{Introduction}

Sorghum [Sorghum bicolor (L.) Moench] is one of the important cereal crops of the world, it ranks fourth among the world cereals in the order of wheat, maize and rice. It is the major source of food and fodder for millions of people in tropics and semi-arid tropics and sorghum is vulnerable to over 150 insect species from sowing to the final crop harvest (Sharma, 1985). Among the different insect pests of sorghum the shoot bug, Peregrinus maidis (Ashmead) (Homoptera : Delphacidae) previously considered to be of minor importance, but now with the introduction of new sorghum genotypes it has become serious pest. Shoot bug can cause a crop loss to an extent of 41 per cent. Both macropterous and brachypterous nymphs and adults suck the sap from the leaves by congregation in the plant whorl and inner sides of the leaf sheath. Severe attack of shoot bug results in leaf chlorosis, stunted growth, shriveled and chaffy grains (Prabhakar et al., 1981).

The top leaves start drying first, but leaf death gradually extends to older leaves and some times, death of the whole plant occurs (Teetes et al., 1983). Severe infestation at boot leaf stage results in twisting of top leaves thus preventing the emergence of panicles (Agarwal et al., 1978). Further, the honey dew excreted by nymphs and adults favours the growth of sooty mould fungus 
(Capnodium sp.) which inhibits the photosynthetic activity

\section{Materials and Methods}

Field trials were conducted using seven genotypes of rabi sorghum viz., DSV 4, DSV 5, BJV 44, Phule yashodha, Phule vasudha, Muguthi, M 35-1 sown during 15th September in a randomized block design (RBD) with three replication in a plot size of $2.4 \times 4.7 \mathrm{~m}$

\section{Biophysical basis of resistance}

\section{Trichome density}

For recording leaf trichome density, the central portion of the fifth leaf from the base was taken from three randomly selected seedlings in each entry at 12-14 days after seedling emergence from each replication. Leaf bits (approximately $0.5 \mathrm{~cm} 2$ ) were placed in $20 \mathrm{ml}$ of acetic acid: alcohol (2:1) in small vials $(1.5 \mathrm{~cm}$ diameter, $5.75 \mathrm{~cm}$ height $)$ for overnight. The cleared samples were transferred to 90 per cent lactic acid in small vials and stored for later observations. For microscopic examination, the leaf samples were mounted on a slide in a drop of water and observed under stereomicroscope at a magnification of $10 \mathrm{X}$. The number of trichomes on both upper and lower leaf surfaces was counted in three microscopic fields selected at random and expressed as trichome density per square millimeter. (No./mm²).

\section{Leaf glossiness}

Intensity of leaf glossiness was recorded at 12 days after seedling emergence in the morning 6.30 to 9.30 hours for clear vision by using 1 5 scale $(1=$ lines with light green, shining, narrow, upward pointed leaves and $5=$ lines with dark green, dull, broad and drooping leaves). Based on this scale the following categories were made.

\section{Seedling vigour}

The seedlings were evaluated for vigour at 14 and 21 days after seedling emergence in the morning 6.30 to 9.30 hours, when seedling growth can be measured properly by using 1 5 scale $(1=$ plants showing maximum growth, leaf expansion and robustness and $5=$ plants showing minimum growth, less leaf expansion and poor adaptation). Based on this scale the following categories were made.

\section{Observations on shoot bug population}

The shoot bug population were recorded (number of adults or nymphs/plant) on five randomly selected plants in each treatment at 30,45 and 60 days after sowing and shoot bug damage was by taking total number of plants in each treatment and number of plants showing yellowing, girdling and stunted growth at 70 days after emergence and percentage of plant damage was worked out. The data were subjected to arcsine transformations before statistical analysis and also rated using (0-9) scale (Table 1).

\section{Results and Discussion}

\section{Trichome density}

Number of trichomes present on both upper and under surface of the leaves at12-14 days after emergence of the crop revealed that, Significantly highest number of trichomes on both upper $\left(20.09 / \mathrm{mm}^{2}\right)$ and lower leaf surface $\left(30.30 / \mathrm{mm}^{2}\right)$ was observed in Phule vasudha followed by Muguthi, BJV44, DSV 4 and M 35-1 were found to be on par with each other and least was recorded in DSV 5 and Phule yashodha. Trichomes were often associated with resistance, more trichome density lesser the infestation of sucking pests 
as it interfere with normal feeding activity and ovipostion. The present findings were in close agreement with Singh and Rana (1986) who reported that, trichomes are frequently associated with shoot fly resistance (Fig. 1).

\section{Seedling vigour}

Seedling vigour recorded on 1-5 scale at 14 and 21 days after emergence of the crop indicated that Seedling vigour recorded at 14 DAE and 21 DAE, Phule vasudha and Muguthi recorded high score of seedling vigour fallowed by remaining genotypes which showed moderate level of vigour with score. The findings are in close agreement with Tarun et al., (2000) who suggested that genotypes having fast seedling growth, long and thin stems and glossy leaves during the seedling stage were comparatively resistant to shoot fly (Tables 2 and 4).

\section{Leaf glossiness}

At 14 DAE, score of leaf glossiness in different genotypes varied from 1.7 to 3.7 The genotype Phule vasudha exhibited high glossiness (1.7) remaining genotypes recorded moderately glossy grade from 2.2 to 3.7 the results are in conformity with Singh and Rana (1986) reported that, glossy leaf surface was frequently associated with shoot fly resistance (Table 3).

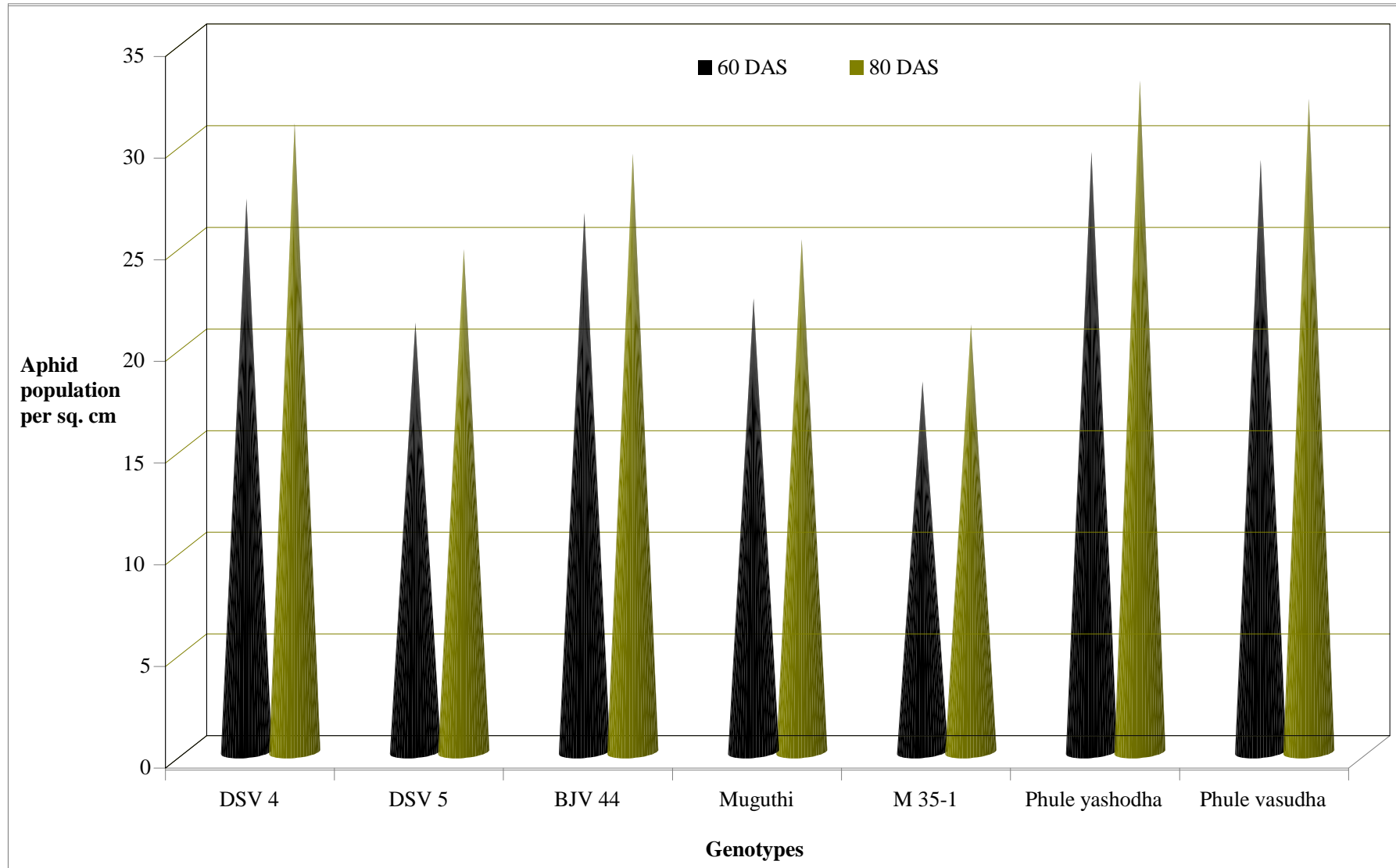

Fig. 1 Response of different genotypes to shoot bug incidence 
Int.J.Curr.Microbiol.App.Sci (2017) 6(10): 707-712

Table.1 Response of different sorghum genotypes to shoot bug incidence

\begin{tabular}{|c|c|c|c|c|c|c|}
\hline \multirow{2}{*}{ Genotypes } & \multicolumn{4}{|c|}{ Shoot bug population/plant } & \multirow{2}{*}{$\begin{array}{l}\text { Shoot bug damage } \\
(\%) 70 \text { DAE }\end{array}$} & \multirow{2}{*}{$\begin{array}{l}\text { Shoot bug } \\
\text { Damage } \\
\text { Grading } \\
(0 \text { - 9) Scale }\end{array}$} \\
\hline & 30 DAS & 45 DAS & 60 DAS & Mean & & \\
\hline $\mathrm{T}_{1}-\mathrm{DSV} 4$ & $9.00^{\mathrm{bc}}$ & $10.20^{\mathrm{abc}}$ & $12.87^{\mathrm{b}}$ & $10.70^{\mathrm{d}}$ & $\begin{array}{c}32.00 \\
(34.44)^{*}\end{array}$ & 3.00 \\
\hline $\mathrm{T}_{2}-\mathrm{DSV} 5$ & $8.40^{\mathrm{b}}$ & $9.47^{\mathrm{ab}}$ & $12.37^{\mathrm{ab}}$ & $10.22^{\mathrm{c}}$ & $\begin{array}{c}29.66 \\
(33.00)^{*}\end{array}$ & 4.00 \\
\hline $\mathrm{T}_{3}-\mathrm{BJV} 44$ & $8.67^{\mathrm{bc}}$ & $9.13^{\mathrm{a}}$ & $12.00^{\mathrm{ab}}$ & $9.80^{\mathrm{b}}$ & $\begin{array}{c}26.66 \\
(31.09)^{*}\end{array}$ & 3.00 \\
\hline $\mathrm{T}_{4}-$ Muguthi & $8.53^{b c}$ & $9.57^{\mathrm{ab}}$ & $12.47^{\mathrm{b}}$ & $10.10^{\mathrm{bc}}$ & $\begin{array}{c}30.66 \\
(33.62)^{*}\end{array}$ & 4.00 \\
\hline $\mathrm{T}_{5}-\mathrm{M} 35-1$ & $9.27^{\mathrm{bc}}$ & $10.53^{\mathrm{abc}}$ & $13.00^{\mathrm{b}}$ & $10.90^{\mathrm{d}}$ & $\begin{array}{c}35.33 \\
(36.47)^{*}\end{array}$ & 4.00 \\
\hline $\mathrm{T}_{6}$ - Phule yashodha & $9.73^{b c}$ & $11.00^{\mathrm{c}}$ & $13.27^{\mathrm{b}}$ & $11.33^{\mathrm{e}}$ & $\begin{array}{c}36.33 \\
(37.06)^{*}\end{array}$ & 4.00 \\
\hline $\mathrm{T}_{7}$ - Phule vasudha & $7.07^{\mathrm{a}}$ & $9.13^{\mathrm{a}}$ & $11.00^{\mathrm{a}}$ & $9.10^{\mathrm{a}}$ & $\begin{array}{c}20.66 \\
(27.03)^{*}\end{array}$ & 2.00 \\
\hline SEm \pm & 0.40 & 0.42 & 0.48 & 0.10 & 1.65 & - \\
\hline $\mathrm{CD}(0.05)$ & 1.20 & 1.26 & 1.44 & 0.30 & 4.95 & - \\
\hline $\mathrm{CV}(\%)$ & 8.83 & 7.89 & 10.63 & 7.32 & 13.48 & - \\
\hline
\end{tabular}


Table.2 Biophysical characters of sorghum contributing shoot bug resistance

\begin{tabular}{|c|c|c|c|c|c|}
\hline \multirow[b]{2}{*}{ Genotypes } & \multicolumn{2}{|c|}{ Trichome density/mm2 } & \multicolumn{2}{|c|}{ Seedling vigour(1 - 5) } & \multirow{2}{*}{$\begin{array}{c}\text { Leaf } \\
\text { glossiness } \\
(1-5) \\
14 \text { DAE } \\
\end{array}$} \\
\hline & $\begin{array}{l}\text { Upper } \\
\text { surface }\end{array}$ & $\begin{array}{l}\text { Lower } \\
\text { surface }\end{array}$ & 14 DAE & 21 DAE & \\
\hline $\mathrm{T}_{1}-\mathrm{DSV} 4$ & 14.6 & 22.4 & 1.0 & 1.3 & 3.7 \\
\hline $\mathrm{T}_{2}-\mathrm{DSV} 5$ & 13.5 & 18.6 & 2.4 & 1.7 & 2.6 \\
\hline $\mathrm{T}_{3}-\mathrm{BJV} 44$ & 15.7 & 23.5 & 2.0 & 2.3 & 2.7 \\
\hline $\mathrm{T}_{4}-$ Muguthi & 18.7 & 26.7 & 1.7 & 2.7 & 2.2 \\
\hline $\mathrm{T}_{5}-\mathrm{M} 35-1$ & 15.7 & 20.7 & 2.4 & 2.7 & 2.6 \\
\hline $\mathrm{T}_{6}$ - Phule yashodha & 13.2 & 18.3 & 2.3 & 2.6 . & 2.4 \\
\hline $\mathrm{T}_{7}$ - Phule vasudha & 20.9 & 30.3 & 3.3 & 3.7 & 1.7 \\
\hline SEm \pm & 0.6 & 0.8 & - & - & - \\
\hline $\mathrm{CD}(0.05)$ & 1.7 & 2.5 & - & - & - \\
\hline $\mathrm{CV}(\%)$ & 6.1 & 6.2 & - & - & - \\
\hline
\end{tabular}

Table.3 Leaf glossiness

\begin{tabular}{|l|l|}
\hline Score & Glossiness category \\
\hline $1.00-2.00$ & High \\
\hline $2.01-4.00$ & Medium \\
\hline $4.01-5.00$ & Low \\
\hline
\end{tabular}

Table.4 Seedling vigour

\begin{tabular}{|l|l|}
\hline Score & Seedling vigour \\
\hline $1.00-2.00$ & High \\
\hline $2.01-4.00$ & Medium \\
\hline $4.01-5.00$ & Low \\
\hline
\end{tabular}

Table.5 Observations on shoot bug population

\begin{tabular}{|c|c|}
\hline Per cent of plant damage by shoot bug & Score \\
\hline 0 & 0 \\
\hline $1-10$ & 1 \\
\hline $11-20$ & 2 \\
\hline $21-30$ & 3 \\
\hline $31-40$ & 4 \\
\hline $41-50$ & 5 \\
\hline $51-60$ & 6 \\
\hline $61-70$ & 7 \\
\hline $71-80$ & 8 \\
\hline$>81$ & 9 \\
\hline
\end{tabular}




\section{Shoot bug population and damage}

Among different genotypes screened Phule vasudha and BJV 44 were found to be superior by recording lowest shoot bug population per plant 9.10 and 9.80 number per plant respectively. While Phule yashodha, M 35-1, DSV 4, DSV 5 and Muguthi recorded maximum number of shoot bugs per plant. The results of the present study are in conformity with the reports of Anaji and Balikai (2006) who reported that the entries, DSV 4, DSV 5 and M 35-1 were highly susceptible by recording higher population (10.3 to 12.5 shoot bugs /plant). Similarly, Subbarayudu (2002) also reported that, the maximum number of shoot bugs per plant was recorded on genotype M 35-1 (25.8) and the fewest on genotype DJ 6514 (3.5) (Table 5).

Significantly lower percentage of plant damage was recorded in Phule vasudha (20.66) with damage scale rating of 2.00 which was on par with BJV44 (26.66) fallowed by all other treatments which were found to be on par with each other. The studies are in conformity with Subbarayudu (2002) who reported that sorghum genotypes viz., Swati, M 35-1, CSH 9, SPV 462 and ICSV were highly susceptible to shoot bug damage.

Among seven genotypes with varying degrees of resistance, the genotypes Phule vasudha and BJV 44 recorded lowest shoot bug population which had highest trichome density, more seedling vigour and less leaf glossiness.

\section{References}

Agarwal, R.K., Verma, R.S. and Bharaj, G.S. 1978. Screening of sorghum lines for resistance against shoot bug. J.N.K.V.V. Res. J., 12: 116.

Anaji, R., and Balikai, R. A., 2006. Correlations of biophysical and biochemical characters with shoot bug incidence in rabi sorghum. Int. J. Agric. Sci., 2 (2): 450-451.

Prabhakar, B., Rao, P.K. and Rao, B.H.K.M. 1981. Note on Hemipterous species complex on sorghum at Hyderabad. Indian J. Agric. Sci., 51: 818-819. Rondani. Insect. Sci. Applic, 7(5): 577587.

Sharma, H. C., 1985. Strategies for pest control in sorghum in India. Tropical Pest Management, 31: 167-185.

Singh, B. U., and Rana, B. S., 1986. Resistance in sorghum to the shoot fly, Atherigona soccata Rondoni. Insect Sci. Appl., 7: 577-587.

Subbarayadu, B., 2002. Shoot bug incidence on sorghum in Southern India. Int. Sorghum and Millet Newsltr, 43: 56-57.

Tarun Verma, Singh, S. P. and Verma, T., 2000. Morpho-physio plant characters associated with shoot fly resistance in sorghum. Haryana Agric. Univ. J. Res., 30 (1-2): 41-43.

Teetes, G.L., Seshu Reddy, K.V., Leuschner, K. and House, L.R. 1983. Sorghum Insect Identification Handbook. Information Bulletin No. 12, International Crop Research Institute for the Semi-Arid Tropics, Patancheru, Andhra Pradesh, India, p.124.

\section{How to cite this article:}

Indhusri Chavan, J.S. Awakanavar and Biradar, A.P. 2017. Biophysical Basis of Resistance against Shoot Bug (Peregrinus maidis) in Different Genotypes of Rabi Sorghum. Int.J.Curr.Microbiol.App.Sci. 6(10): 707-712. doi: https://doi.org/10.20546/ijcmas.2017.610.087 